\title{
BMJ Open Novel 3D printable powered air purifying respirator for emergency use during PPE shortage of the COVID-19 pandemic: a study protocol and device safety analysis
}

Jorge Nagel, ${ }^{1}$ Catherine Gilbert $(1),{ }^{1}$ Juan Duchesne ${ }^{2}$

To cite: Nagel J, Gilbert C, Duchesne J. Novel 3D printable powered air purifying respirator for emergency use during PPE shortage of the COVID-19 pandemic: a study protocol and device safety analysis. BMJ Open 2021;11:e049605. doi:10.1136/ bmjopen-2021-049605

- Prepublication history for this paper is available online. To view these files, please visit the journal online (http://dx.doi org/10.1136/bmjopen-2021049605).

JN and CG contributed equally.

Received 29 January 2021 Accepted 06 August 2021
Check for updates

(c) Author(s) (or their employer(s)) 2021. Re-use permitted under CC BY-NC. No commercial re-use. See rights and permissions. Published by BMJ.

${ }^{1}$ Tulane University School of Medicine, New Orleans, Louisiana, USA

${ }^{2}$ Surgery, Tulane University School of Medicine, New Orleans, Louisiana, USA

Correspondence to Catherine Gilbert; catherinegilbert24@gmail.com

\section{ABSTRACT}

Objectives To design a low-cost 3D printable powered air-purifying respirator (PAPR) that meets National Institute for Occupational Safety and Health (NIOSH) standard for flow rate and Occupational Safety and Health Administration (OSHA) standard for particle filtration for loose-fitting PAPRs and that can be made with a 3D printer and widely available materials.

Design Detailed description of components, assembly instructions and testing of a novel PAPR design in an academic laboratory following respective protocols. The assembled PAPR must meet NIOSH standards of flow rate, $170 \mathrm{~L} / \mathrm{min}$; OSHA fit factor for particle filtration, $\geq 250$ and maintain positive pressure during regular and deep breathing.

Main outcome measures The PAPR design was run through a series of tests: air flow (L/min), particle filtration (quantitative and qualitative) and positive pressure measured inside the helmet $(\mathrm{mm} \mathrm{Hg})$.

Results Flow rate was $443.32 \mathrm{~L} / \mathrm{min}$ (NIOSH standard: minimum $170 \mathrm{~L} / \mathrm{min}$ ) and overall fit factor for particle filtration was 1362 (OSHA pass level: $\geq 500$ ), $n=1$. The device passed qualitative particle filtration, $n=2$, and measured peak pressure of $6 \mathrm{~mm} \mathrm{Hg}$ ( $>0 \mathrm{~mm} \mathrm{Hg}$ indicates positive pressure) in the helmet, $\mathrm{n}=1$.

Conclusions The Hygieia PAPR is a low-cost, easily accessible, just-in-time 3D printable PAPR design that meets minimum NIOSH and OSHA standards for flowrate and particle filtration for loose-fitting PAPR devices to be made and used when industry-made designs are unavailable.

\section{INTRODUCTION}

As of June 2021, the COVID-19 pandemic has caused approximately 3.84 million reported deaths worldwide. ${ }^{1}$ Fortunately, the vaccination effort that began in December 2020, has resulted in the decline of incidence and deaths from COVID-19 since early $2021 .^{2}$ Current evidence suggests the COVID-19 virus transmits via respiratory droplets between people in close proximity indoors, thus putting healthcare workers at
Strengths and limitations of this study

- This study details a low-cost novel 3D printable powered air-purifying respirator (PAPR) that meets National Institute for Occupational Safety and Health (NIOSH) and Occupational Safety and Health Administration (OSHA) minimum standards for flowrate and particle filtration, respectively for loosefitting PAPR devices that can be made by anyone with access to the internet, a 3D printer and a general merchandise store.

- This design can be used to protect healthcare workers around the world while they perform essential procedures when the supply of industry-made designs is low. Though this design was tested in an uncertified academic laboratory, not all NIOSH and OSHA standards were tested necessary for official certification, and it was not tested on end-users for clinical feedback.

- Current published alternate novel PAPR designs are very valuable but either contain expensive proprietary components or impede important sensory faculties (visual field, hearing ability).

- Downside of over 30 hours of print time should be weighed against by the simplicity and cost benefits of this design.

- Persons must have access to a 3D printer and a general merchandise store or online ordering and delivery which is not always available in rural, resource-limited settings.

high risk. ${ }^{3}{ }^{4}$ Personal protective equipment (PPE) is one of the most important means by which healthcare workers are protected. However, at the start of the pandemic, hospitals across the globe experienced shortages of key equipment needed to safely care for these patients. ${ }^{56}$ For months, hospitals and ambulatory facilities across the globe struggled with inadequate supply. ${ }^{6-8}$

In addition to PPE supply not meeting the high demand, the cost of PPE increased as 


\section{Box 1 Helmet}

1. Trim the 7 mil clear binding cover sheet to fit jaw piece. Place the cover sheet into the slit in the head piece.

2. Align and fit head piece+cover sheet together with the jaw piece. Cover sheet will fit into slit in jaw piece. Use cyanoacrylate glue to secure (figure $5 A, B$ ).

3. Cut shower cap down the centercentre about halfway; hot glue the two sides where the upper jaw piece meets the head piece. Carefully continue to separate cap down centercentre so that the sides can be hot glued down the jaw piece (figure $5 \mathrm{C}-\mathrm{F}$ ).

4. Measure and cut 8 inches of foam weatherstrip tape and place adhesive side against the inner portion of helmet where the forehead will be. Cover top with second shower cap (figure 4A, helmet on right). Cut 8 inches of elastic and tie to boat-cleat protrusions of head piece (figure $4 \mathrm{~B}$ arrow). See figure $4 \mathrm{C}$ for four views of completed helmet design.

hospitals were required to have more of it on hand. ${ }^{9}$ In March 2020, the WHO called on industry and governments around the world to increase manufacturing as the supply of PPE was dangerously low. ${ }^{10}$ Though industry manufacturing efforts escalated, the global 3D printing community began to produce PPE to help those combating COVID-19 before industry-made designs could become available. ${ }^{112}$ One type of PPE that has become increasingly important is the powered air-purifying respirator (PAPR). A PAPR pulls or pushes air through a highefficiency particulate arrestance (HEPA) filter (99.97\% efficacy at $0.3 \mu$ particle size) and directs the air into an enclosed space to create a positive pressure environment for persons wearing the device. The device provides both a filtered air environment as well as a physical barrier against droplets and particulates. ${ }^{13}$

In the early months of the pandemic, healthcare facilities around the globe struggled to provide workers with adequate PPE. However, hospitals in low-resource countries were at an even greater disadvantage as they share the same supply chain as wealthier countries with less bargaining power. ${ }^{6}$ Given the shortage, barriers to access, and expense of PPE, the authors were inspired to design an emergency use 3D printable PAPR that can be made with widely available materials and a 3D printer for onetenth of the cost of an industry-made design meeting the National Institute for Occupational Safety and Health (NIOSH) standard for flow rate and Occupational Safety and Health Administration (OSHA) standard for particle filtration for loose-fitting PAPR devices.

\section{METHODS}

\section{Components}

The 3D printed parts were created on an Ender 5 Plus using a $0.4 \mathrm{~mm}$ nozzle and using the default 'standard quality' slicer settings from Cura with the following parameters: layer height: $0.2 \mathrm{~mm}$, line width: $0.4 \mathrm{~mm}$, wall thickness: $0.8 \mathrm{~mm}$, wall line count: 2 , top/bottom layers: 4, infill: $20 \%$, infill pattern: zig zag. Filament was polylactic acid, no rafts or supports were used. Four pieces were printed (print times hour:min, weight and length of plastic required, cost): head piece $(7: 29,108 \mathrm{~g}, 37.98 \mathrm{~m}$, US\$2.10), jaw piece $(3: 44,49 \mathrm{~g}, 17.17 \mathrm{~m}$, US $\$ 0.95)$, filter side of power box $(7: 10,126 \mathrm{~g}, 44.39 \mathrm{~m}$, US\$2.46) and battery side of power box $(13: 18,220 \mathrm{~g}, 77.38 \mathrm{~m}$, US $\$ 4.29)$. Files can be found online (https://www.thingiverse.com/ thing:4292619).

The filter used is a 3M HEPA filter (3M, Saint Paul, Minnesota, USA) intended for air filtration and rated and certified to filter $99.97 \%$ of all airborne particles, including dust, allergens, bacteria, viruses and more. The filter life is approximately 6 months based on 12 hours of use per day. ${ }^{14}$

The authors chose to use two 12V Milwaukee batteries (Milwaukee Tool, Brookfield, Wisconsin, USA), used for power tools, because these tools are often a common household item or can easily be purchased if not on hand. Battery charge time is $40 \mathrm{~min}$ at $3 \mathrm{~A}$. The hose chosen is one of the more easily accessible hoses available in a hospital and can be found in a manual resuscitator kit (Ambu, Columbia, Maryland, USA). One-inch corrugated tubing is also widely available online or at general merchandise stores. The fan is a centrifugal DC blower, $12 \mathrm{~V}, 1 \mathrm{~A}$, with a maximum airflow of 16 cubic feet per minute (COM-11270, SparkFun Electronics, Niwot, Colorado, USA). A centrifugal blower was chosen primarily for the energy efficiency, increased air speed and increased rate of airflow as compared with an axial fan.

Additional components needed are 4, 22-16-gauge male spade connectors, and a DC motor PWM speed controller (3V 6V 12V 24V 35V DC 5A 90W). Other hardware needed: two plastic shower caps, one 7 mil PVC clear binding cover plastic sheet (CSF Binding Supplies, Norton Shores, Michigan, USA), utility belt (Husky, Bolton, Caledon, Canada), thermal glue gun (Elmer's Products, Atlanta, Georgia, USA), cyanoacrylate (CA)

\section{Table 1 Power box}

Battery side Filter side

1. Align $12 \mathrm{~V}$ blower fan with indices, use hot glue gun to apply ring of glue around air-inlet to seal.

$\begin{array}{ll}\text { 2. Connect four spade connectors } & \text { 7. Align clam shell } \\ \text { to four wires, two longer to travel the } & \text { pieces and press } \\ \text { length of the box (see figure } 6 \text { for } & \text { together. } \\ \text { wiring diagram). } & \end{array}$

3. Thread wires through slots in battery 8 . Fit utility belt through holder pieces and use hot glue to seal slots. wires and connectors at the bottom.

4. Complete battery, fan and controller 9. Connect hose to circuit as depicted in the wiring diagram (figure 6); place speed head piece and power controller in slot above fan.

\section{Plug $12 \mathrm{~V}$ batteries into holders.}

HEPA, high-efficiency particulate arrestance. 


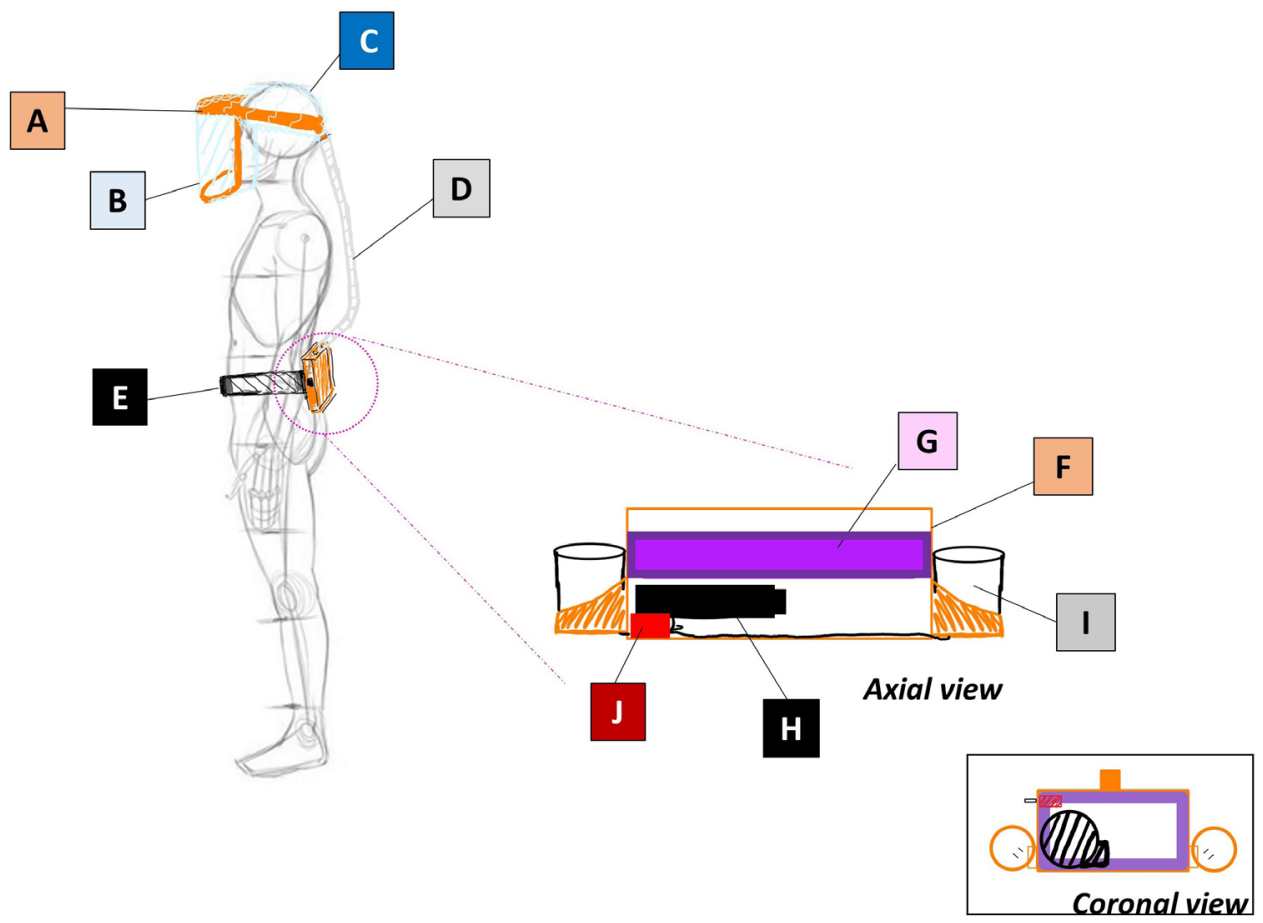

Figure 1 Schematic diagram of labelled components. A: 3D printed head and jaw pieces; B: 7 mil PVC sheet; C: shower cap; D: ventilation tubing/corrugated hose; E: work belt; F: 3D printed power box; G: 3M high-efficiency particulate arrestance air filter; H: 12V blower fan; I: 12V Milwaukee rechargeable battery; J: DC motor speed controller.

glue (Loctite, Düsseldorf, Germany), 3/32 inch abrasionresistant elastics cord (McMaster-Carr, Elmhurst, Illinois, USA), and $3 / 4$ inch $\times 7 / 16$ inch rubber foam weatherstrip tape (Thermwell Products, South Mahwah, New Jersey, USA).

All components, including the HEPA filter, are widely available online, at home improvements stores or general merchandise store. A supply shortage of any one component is possible; however, it is unlikely.

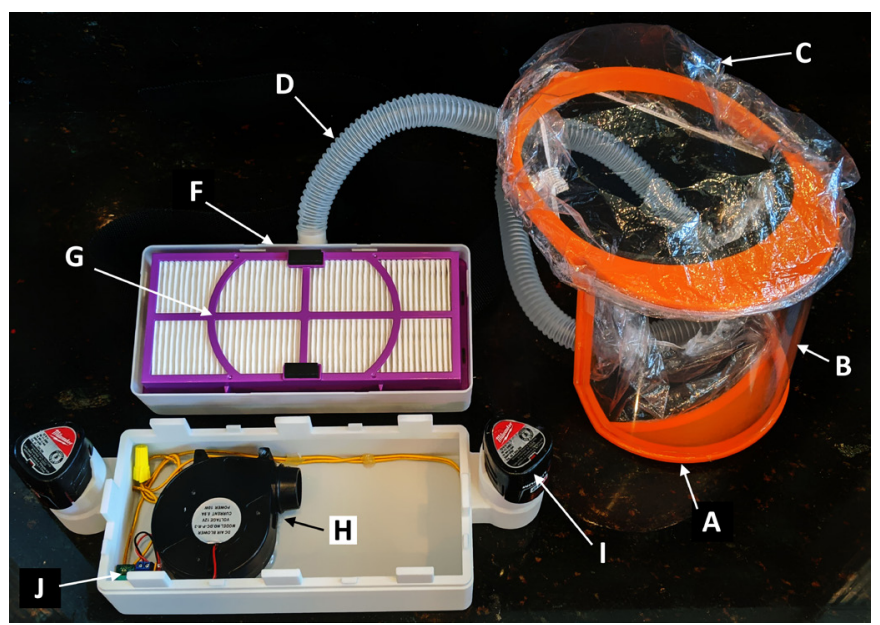

Figure 2 Assembled powered air-purifying respirator with open power box. A: 3D printed head and jaw pieces; B: 7 mil PVC sheet; C: shower cap; D: ventilation tubing/ corrugated hose; F: 3D printed power box; G: 3M highefficiency particulate arrestance air filter; $\mathrm{H}$ : 12V blower fan; I: 12V Milwaukee rechargeable battery; J: DC motor speed controller. (Work belt, E in figure 1, is not pictured.)
Patient and public involvement

No patients involved.

Instructions

Box 1 and table 1 (see figures 1 and 2 for schematic and overview).

\section{Configuration and mechanism}

The blower fan is used to create a positive pressure in the chamber prior to the filter. Air is thus forced through the filter onto the downstream conduit, which is at all times at a greater pressure than ambient. This positive pressure gradient ensures that no unfiltered air enters the system despite imperfect seals to the outside. Figure 3 demonstrates the flow of air from the blower, through the filter and out the outlet of the power box through the hose. The seal between the HEPA filter and the filter side of the power box is the most important seal of the design and ensures that no unfiltered air goes through the helmet to the wearer. To ensure a tight seal, the built-in adhesive rubber-seal around the HEPA filter is pressed into the lip of the filter side (figure $3(\mathrm{~B}(\mathrm{a}))$ ) by the prongs on the battery side (figure $3(\mathrm{~A}(\mathrm{a}))$ ), maintaining constant pressure, thus ensuring a secure seal around the filter.

The connections between the hose and the power box and the helmet are all interference fit. The outside diameter of the 3D printed parts was intentionally enlarged such that it creates an interference with the inner diameter of the hose. Additionally, a ridge was added to the 3D printed connection on the helmet and filter side to match the corrugations of the hose, thus increasing seal integrity and preventing accidental disconnection 

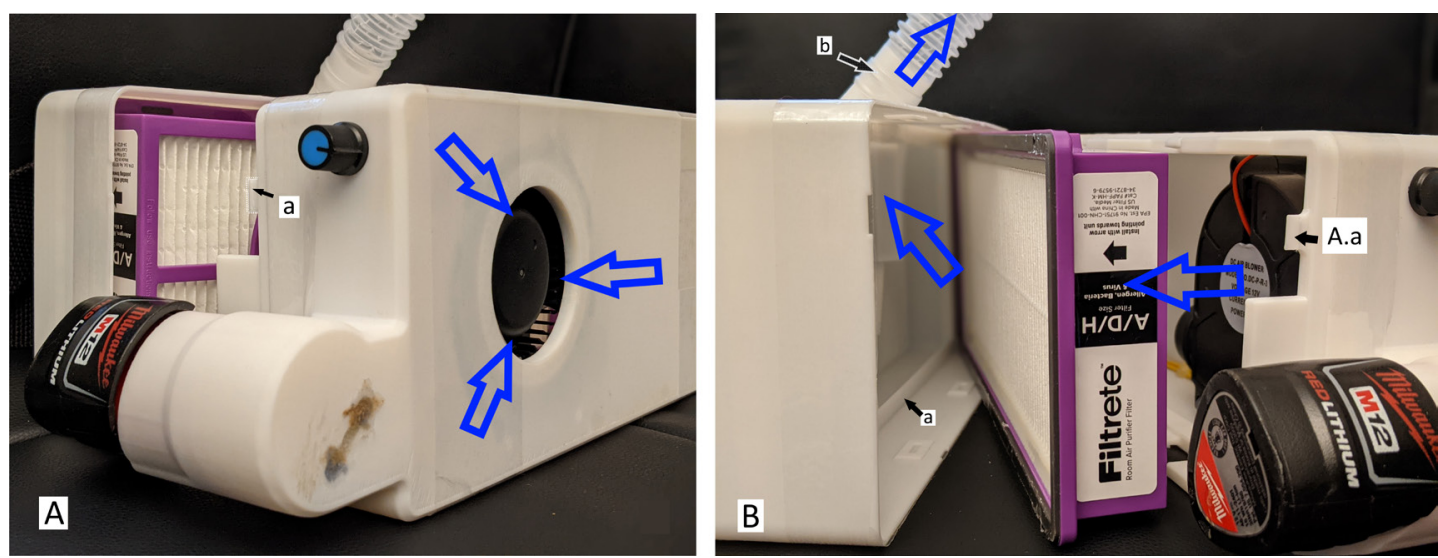

Figure 3 Hygiea power box dissembled to visualise specific components and direction of air-flow (as indicated by the blue arrows). The prongs on the battery side $(A(a))$ press the high-efficiency particulate arrestance filter into the lip of the filter side $(B(a))$. A ridge on the hose connection increases seal integrity and prevents accidental disconnection $(B(b))$.

(figure 3(B(b))). We acknowledge that there are imperfect seals throughout the device. However, so long as positive pressure is maintained in the helmet, the air leaking through the seals may decrease efficiency but does not compromise the filtered air.

\section{TESTING/RESULTS}

Air flow rate was calculated by measuring air speed and multiplying it by the cross-sectional area at the measurement site. Air speed was determined using a HoldPeak HP-866B-APP anemometer (Zhuhai JiDa Huapu Instrument, Zhuhai, China) with an accuracy of $\pm 5 \%$. 3D printed adapters were used to place the anemometer in series between the hose and helmet. The helmet was donned and the power was turned on full. The crosssectional area of the anemometer was measured at $0.0026 \mathrm{~m}^{2}$ and air speed measured at $2.2 \mathrm{~m} / \mathrm{s}$, equalling a flow rate of $0.0074 \mathrm{~m}^{3} / \mathrm{s}$ or $443.32 \mathrm{~L} / \mathrm{min}$, well above the NIOSH minimum requirement of $170 \mathrm{~L} / \mathrm{min}$ for loose-fitting PAPRs. ${ }^{15}$ Airflow measurements were taken while the device was being worn and the units were in operation. The current prototype has demonstrated an approximate run time of $45 \mathrm{~min}$.

Particle testing followed the OSHA 29CFR1910.134, Appendix A.C.3. Ambient aerosol condensation nuclei counter quantitative fit testing protocol. ${ }^{16} \mathrm{~A}$ port was placed at the base of the jaw piece by drilling a $4 \mathrm{~mm}$ hole and placing a Portacount test probe 8025 -N95R (TSI, Shoreview, Minnesota, USA). CA glue was used to seal the probe against the plastic. The 'mask' intake was connected to the port, while the 'ambient' intake was $4 \mathrm{~cm}$ below. The particle counter used was the Portacount Pro + Model 8038 (TSI). The non-hazardous test aerosol was created using an ultrasonic humidifier with tap water to generate particles.

The subject $(\mathrm{n}=1)$ donned the helmet with the installed particle counter and particle count was measured with the PAPR powered on while the subject performed different exercises each for $1 \mathrm{~min}$. Fit factor (particle concentration outside the respirator divided by the particle concentration inside the respirator) was calculated for each of the following exercises (passing level is $\geq 500)^{16}$ : normal and
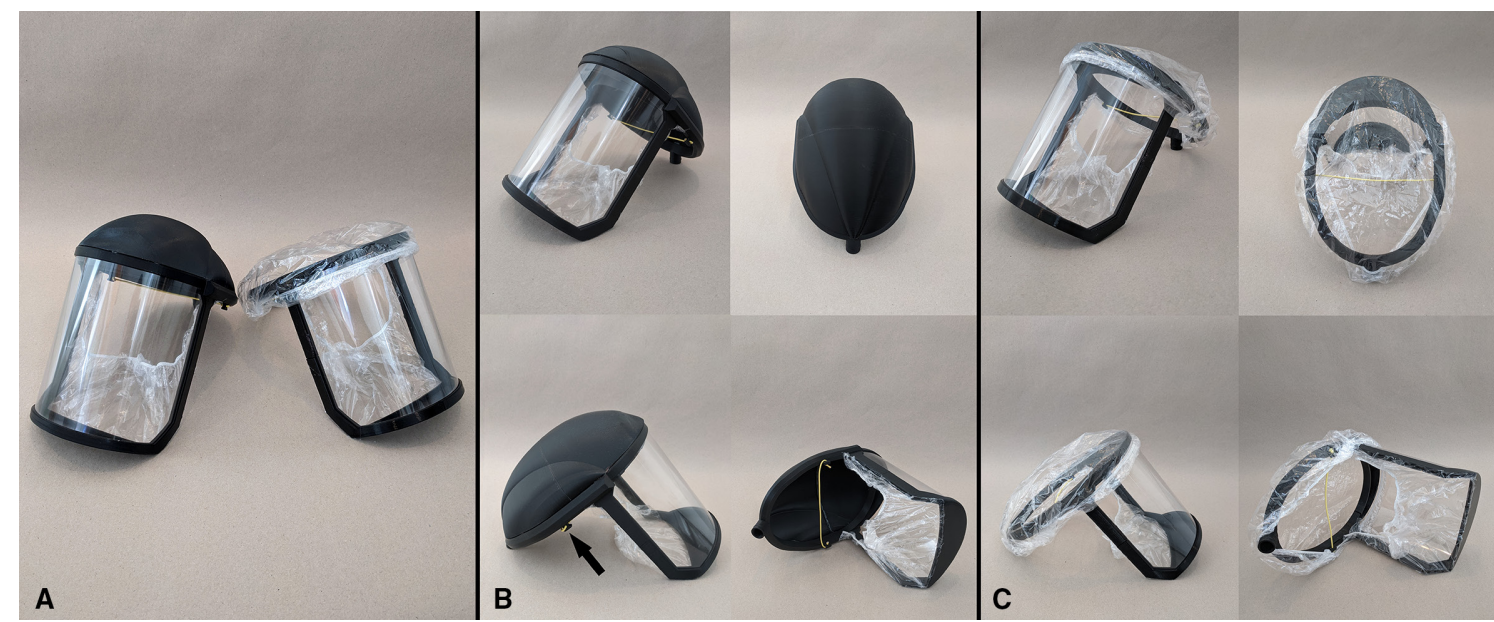

Figure 4 (A) Side-by-side comparison of assembled 3D printed helmet with optional top shell (left) or shower cap (right). (B) Four views of assembled helmet with shell. Arrow pointing to boat-cleat attachment-point for elastic. (C) Four views of assembled helmet with shower cap. 

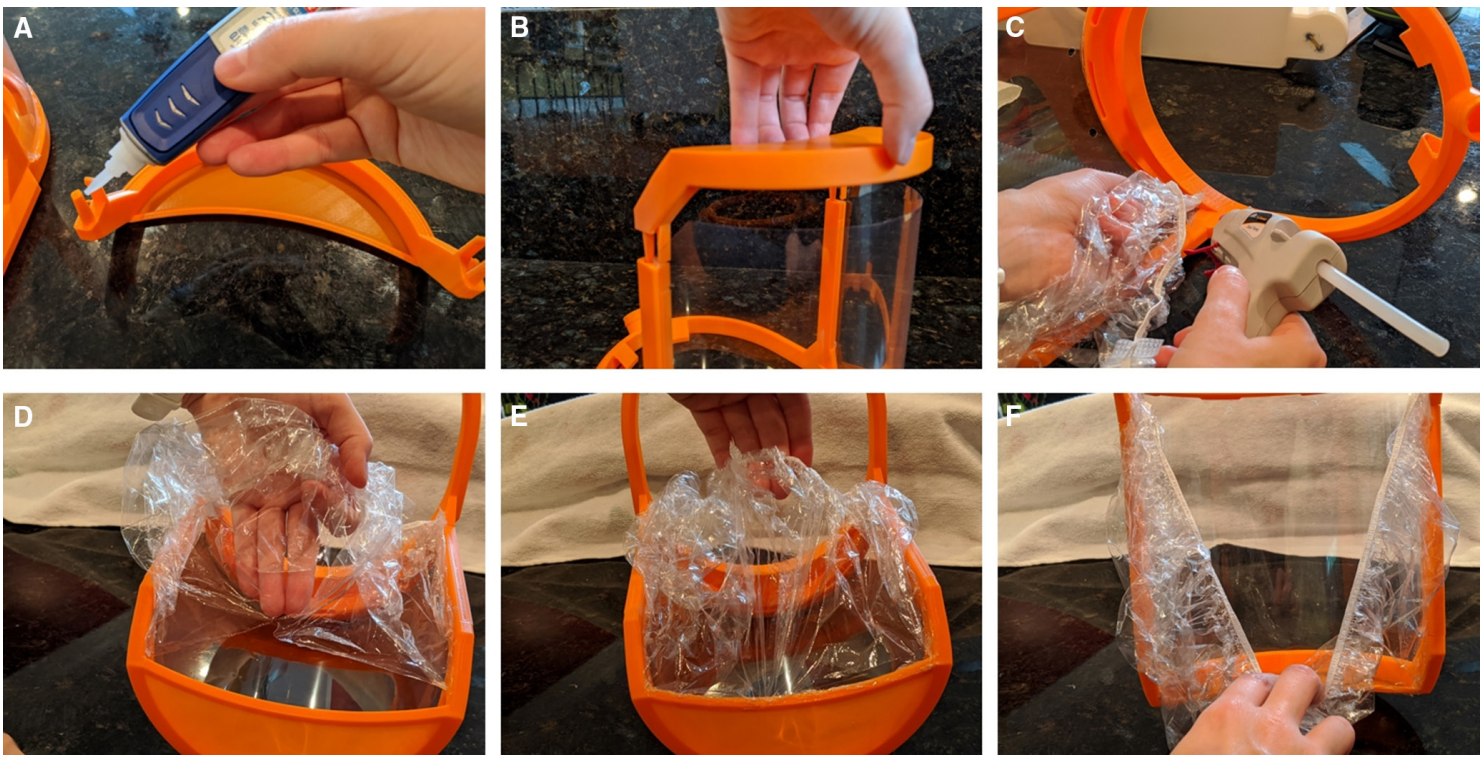

Figure 5 Assembly of jaw piece and application of shower cap. (A) Apply cyanoacrylate glue to jaw piece joint. (B) Align jaw piece and head piece with 7 mil cover sheet and join. (C) Once shower cap is cut down the centre about halfway; hot glue the two sides where the upper jaw piece meets the head piece. (D-F) Carefully continue to separate cap down centre so that the sides can be hot glued down the side and to the centre of the jaw piece.

deep breathing (1433 and 1035, respectively), head side to side and up and down (1119 and 1384, respectively), talking (2515) and bending over (1663). Grimacing was omitted due to facial expression being irrelevant in a loose-fitting PAPR. Overall fit factor for particle filtration was 1362 (OSHA pass level: $\geq 500$ ).

Qualitative fit test was assessed using the 3M Ft-30 N95 Respirator protocol and $3 \mathrm{M}$ bitter formula testing kits (3M).${ }^{17}$ The bitter formula was nebulised in the hood with the PAPR powered on for the full series of movements (see earlier for movements done during particle testing). The test was then repeated with the bitter formula nebulised immediately adjacent to the blower intake with

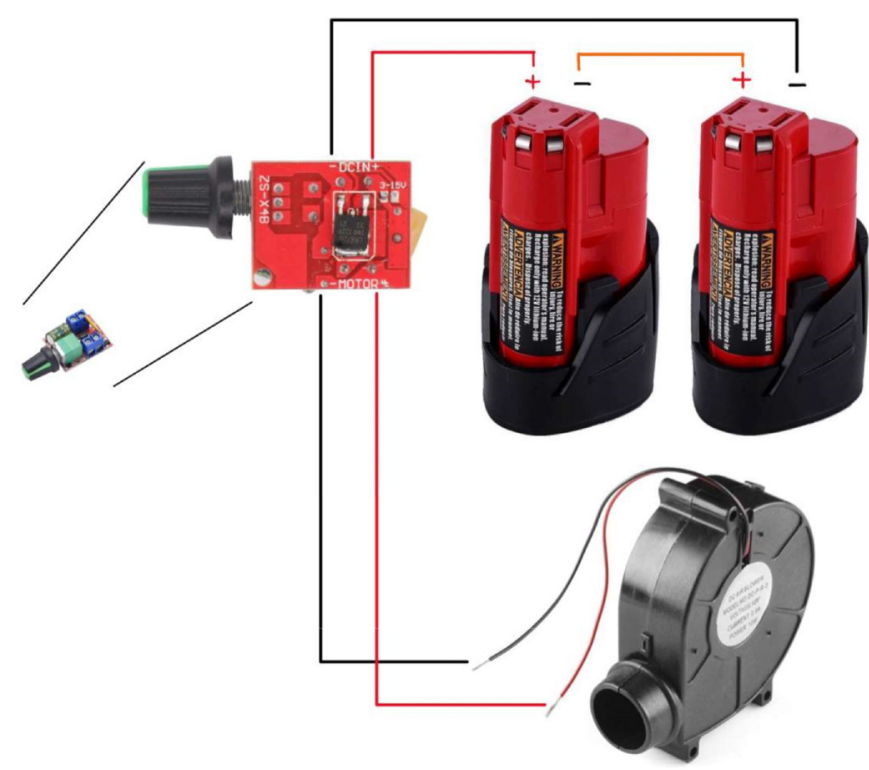

Figure 6 Wiring diagram for DC controller, batteries and blower. the full series of movements. The subjects $(n=2)$ were determined to be sensitive to the bitter formula, but the bitter formula was not tasted at any point during either test by either participant. Qualitative testing was done to mimic the testing done during N95 fit testing. This testing is quick and easy to perform and is widely available in healthcare facilities or can be purchased online for minimal cost. A particle counter is expensive and less available in non-university healthcare settings.

Positive pressure was measured by drilling a 6/32-inch port in the jaw piece of the helmet where an arterial line pressure sensor (TruWave Disposable Sensor, Edwards Lifesciences Corp., Irvine, California, USA) was placed and thermal glued for a secure seal. The pressure transducer measured a peak pressure of $6 \mathrm{~mm} \mathrm{Hg} \pm 1 \mathrm{~mm}$ $\mathrm{Hg}$ indicating positive pressure in the helmet with both regular and deep breathing. Other exercises were not performed as change in elevation of the helmet would affect the pressure reading by changing the water column of the arterial line. This test demonstrates that positive pressure is maintained throughout the system, indicating that contaminated ambient air cannot leak into the system despite potential imperfect seals. Note, all qualitative and quantitative tests were done on the same prototype with the pressure test being performed last as the sensors altered the integrity of the jaw piece.

PAPR devices are often tested for their ability to filter silica dust, usually for mining or other dusty work environments. Our PAPR device is intended for the healthcare setting and this test was deemed unnecessary.

To make the PAPR more environmentally friendly, the authors designed an optional shell that can be printed and glued to the top of the helmet (figure 4A helmet on left, figure 4B 4 views of completed helmet with 
optional shell). The shell is split into front and rear pieces (hour:min, weight and length of plastic required, cost): front (4:11, $69 \mathrm{~g}, 24.6 \mathrm{~m}$, US $\$ 1.34)$, rear (2:41, $42 \mathrm{~g}$, $14.88 \mathrm{~m}$, US $\$ 0.82$ ). This option allows the top to be wiped down as opposed to disposing of the top shower cap. (Testing data were collected on the original model with a second shower cap top instead of this shell. However, the optional shell does not induce any changes to the functional aspect of the jaw and headpiece and thus would cause no changes in the functional aspect of the overall respirator.)

\section{DISCUSSION}

\section{Principal findings}

The Hygieia PAPR is a novel 3D printable PAPR design that meets minimum standards for NIOSH and OSHA flow-rate and particle filtration, respectively, for loosefitting PAPR devices. Additionally, the PAPR demonstrated positive pressure inside the helmet during normal and deep breathing.

\section{Strengths and weakness}

Compared with N95 respirators, PAPRs have a higher protective factor, provide more comfort to the wearer for prolonged periods of time, remove concerns of poor N95 fit and seal, and may decrease the effort needed to maintain the work of breathing. ${ }^{18-20}$ PAPRs may be especially useful protection in aerosolising procedures like dynamic resuscitation and nearly eliminate fogging of eye wear, shields and hoods. ${ }^{4181921}$ Additionally, N95 respirators have been shown to alter cerebral blood flow and cause headaches which can be alleviated by the addition of a PAPR. ${ }^{22}$

Though the individual cost of an N95 mask is small (US\$1.50), the true cost lies in fit testing. ${ }^{21}$ If an N95 respirator does not fit, or an improper size is used, a seal cannot be achieved and the mask will not provide full protection. ${ }^{23}$ Additionally, depending on the respirator model and accuracy of fit testing, 1\%-20\% of wearers will have an inappropriate respirator assigned to them, putting them at risk to potential exposures. ${ }^{24}$ A loosefitting PAPR does not require fit testing and is able to be worn with facial hair. ${ }^{19-21}$ However, an industry-designed PAPR can cost from US $\$ 900$ to over US $\$ 1200$ with the addition of the battery and charger. ${ }^{21}$ In comparison, the PAPR design detailed in this paper is one-tenth of the cost, approximately US $\$ 120$ for the materials.

One of the most signficant advantages of this PAPR design is the ability to use components from different manufacturers than those detailed in the Methods section so long as it has the same specifications. As an example, the batteries must be $12 \mathrm{~V}$ drill batteries, but the company and manufacturer do not affect the function of the design (the battery, or series of batteries, used should be rated so that they provide enough discharge current to drive the blower).
The nature of 3D printing allows for rapid, easily executable changes. An example would be the ability to change the battery cartridges to fit a different brand of drill battery. If working on a printer with a bed smaller than that of the Ender 5 Plus, the helmet can be split up into parts and glued together. Though print times may be a concern, if orchestrated properly, a PAPR can be made in less than 33 hours of total printing time and can be cleaned, reused and shared (so long as proper cleaning is performed between each use). The drawback of a prolonged total print time is potentially outweighed by the simplicity and cost benefits of this design.

The helmet length and width were designed to be large enough to accommodate the majority of head dimensions. However, if the current design does not fit a given user several adjustments can be made. The foam in the front of the helmet is primarily for comfort, any other padding material can be used to increase or decrease the helmet diameter, so long as the padding material does not cover the vents in the helmet. Similarly, the elastic used can be exchanged for another type of elastic, string or tie, that will help secure the helmet to the wearers head. Finally, if the current dimensions of the helmet or jaw piece still do not fit the wearer comfortably, they can be altered in the .stl file before being printed. The shower cap attached to the jaw piece can be adjusted for comfort by glueing additional shower cap elastic to the jaw piece on each side where it meets the head piece. These adjustments are for comfort and will not alter the flow-rate, particle filtration or positive-pressure of this loose-fitting PAPR design.

The fan has been intentionally placed before the filter to ensure positive pressure throughout the system. A fan placed after the filter would create a negative pressure and the potential for unfiltered air to seep into the system. Additionally, potential particulates generated by the fan itself are forced to go through the filter, thus preventing them from reaching the user. Commercial units often place the fan after the filter. However, these novel methods of user-dependent manufacturing lack the stringent sourcing controls otherwise used in traditional medical equipment manufacturing and thus we believe it is better to ensure the user's safety. Concerns about difficulty cleaning the fan input impeller are mitigated by the air being filtered after the fan.

The $12 \mathrm{~V}$ batteries are wired in series resulting in a higher voltage with a lower current system to drive adequate airflow. It also allows for a more robust system given the flexible nature of the hose connecting the power box to the head piece and the critically important maintenance of high flow rate. The authors acknowledged using a 12V fan is non-ideal and would recommend using a $24 \mathrm{~V}$ fan instead. 24V blower fans are can be found at similar cost and can likely be used with similar results.

Cleaning the PAPR can be easily achieved by using a bleach wipe. A recent study by Welch et al demonstrated that SARS-CoV-2 and two other surrogate coronaviruses (MHV and 229E) on 3D printed material were completely inactivated by a single application of $10 \%$ 
bleach, ammonium Quaternary, $3 \% \mathrm{H}_{2} \mathrm{O}_{2}$, or exposure to $70^{\circ} \mathrm{C}$ dry heat. ${ }^{25}$ Other sources have shown sterilisation by low-temperature hydrogen peroxide gas plasma, though this may not be a viable option for many settings. ${ }^{26}$ Some elements of the PAPR may not be sufficiently cleaned with a wipe, like the utility belt made with poly web material. For thorough cleaning, the belt should be removed from the power box and submerged in a basin filled with either ethanol or isopropyl alcohol. ${ }^{27}$ Additionally, alternate belt materials that are easier to clean can be used to strap the power box to the wearer.

The authors were inspired to design the Hygieia PAPR as an option for emergency-use PPE when industrymade designs are unavailable. PPE is a key component of controlling infection spread in both healthcare settings and the community, but a survey of hospitals in low-resource countries for the past 5 years confirms low quantities of available PPE; this supply shortage was made critical by the pandemic. ${ }^{628}$ In March, hospitals in Kathmandu, Nepal, commissioned the National Innovation Center to innovate and create PPE, allowing them to circumvent the global PPE supply chain. ${ }^{29}$ It is these types of organisations around the world with whom we wish to connect, correspond and collaborate to create the most effective tools for the greatest number of people.

\section{Limitations}

Our testing was done in the academic laboratory at Tulane University which, though accurate, is not a formal, nationally certified testing centre. Though we meet the minimum standards for flow rate (NIOSH) and particle filtration (OSHA), we did not perform all the tests that would qualify us for formal NIOSH and OSHA PAPR certification. Several tests performed during this certification process are to test the integrity of the filter (NIOSH-42 CFR, Part 84). ${ }^{15}$ We used a 3M HEPA filter previously certified to meet these standards and emphasised a tight seal between the filter and power box to ensure adequate filtration. $^{30}$

Certified PAPRs undergo many more tests than were performed on the design detailed in this paper (housing sealing testing, oil aerosol testing, communicating performance testing, and control systems alarms for flow rate testing). However, due to lack of access to appropriate equipment, we did not perform these tests on the PAPR design. We narrowed our focus to flow rate and particle filtration, as they are the most relevant variables in an emergency situation. We used the OSHA 29CFR1910.134, Appendix A.C.3 protocol for particle filtration. The nonhazardous test aerosol used was created with an ultrasonic humidifier and tap water. According to the protocol, the preferred aerosols used are corn oil, polyethylene glycol 400 (PEG 400), di-2-ethyl hexyl sebacate or sodium chloride. ${ }^{16}$ In order to obtain NIOSH certification, the manufacturer needs to be certified for minimum quality control standards. This PAPR does not have official NIOSH or OSHA certification and should only be used in emergency situations, and users should proceed with caution when considering use in healthcare settings. The Hygieia PAPR was not tested on end-users for clinical feedback and was not, to the authors knowledge, used in clinical or high-level PEE situations.

\section{In relation to other studies}

Some PAPR designs have already been published using 3D printable adapters and parts. ${ }^{13} 3132$ Erickson et al observed that Stryker Flyte helmet worn during orthopaedic surgery is, in-essence, a PAPR without the filtration. The authors 3D printed an adapter to connect HEPA filters to the airintake system; thus, creating a PAPR with minimal addition to a pre-existing system. ${ }^{13}$ This is an innovative way of using available resources. However, not all hospitals are equipped to perform orthopaedic surgery and do not have the Stryker Flyte helmets on hand. Additionally, the hood for the helmet covers the ears which can decrease the hearing ability of the wearer, potentially detrimental to communication between healthcare workers in emergent situations.

Hubbard et al modified a Scott Safety self-contained breathing apparatus (SCBA) into a PAPR, primarily for fire fights and other first responders to use during the PPE shortage. An SCBA uses compressed air fed to an airtight mask via a pressure regulator, providing clean air to the wearing, but impractical and cost prohibitive for long-term use. The authors modified the SCBA mask with a HEPA filter at the air intake attached to a powered fan in a $3 \mathrm{D}$ printed casing, creating a PAPR ${ }^{32}$ Similar to the design by Erickson $e t$ al, this PAPR is a cost-effective solution if the SCBA mask is readily available. Additionally, the design of the SCBA mask might impede full visual field necessary for medical procedures.

Nazarious et al designed a mini wearable cleanroom and biosafety system or, a Pressure Optimized PowEred Respirator. The blower fan and power system are similar to that of the Hygieia power box with the addition of a safety-fuse and a lithium ion rechargeable powerbank as the power source. The main difference lies in the hood comprised a face shield frame, the hood adapter and flange, the helmet fitting (adjustable head straps) and SMS head fabric. The SMS material used for the hood and clean room garment set is single use. ${ }^{31}$ This is an inexpensive helmet-based respirator system that can be made with widely available components. However, it costs approximately US $\$ 250$ per device, compared with US $\$ 120$ for the Hygieia PAPR, and has more, small components that add to the complexity of the device.

These innovations are valuable additions to the literature in a time of worldwide PPE shortages and are tailored to specific settings and environments. However, the incorporation of more expensive or difficult to obtain components, using designs with many components, or working within the limitations of the visibility and aural requirements of certain healthcare settings, may make these designs less optimal for the more resource limited healthcare settings. 
The Hygieia PAPR is inexpensive, requires no proprietary parts and has a minimal number of components. The design of the helmet allows for nearly full visual field and provides full coverage of the rest of the face and critical orifices. Some PAPR designs use a hood to increase coverage (ears, hair and shoulders), but can make communication challenging particularly in critical moments of care. ${ }^{21}$ This PAPR is a valuable addition to the literature and pool of options for emergency PPE.

\section{Unanswered questions and future research}

Aspects that warrant further investigation are elements of efficiency and optimisation. The imperfect seals do not optimise the power and positive pressure generated. Qualitative and quantitative testing will need to be redone with a $24 \mathrm{~V}$ fan. The current batteries are widely available but are heavy, bulky, and do not have an extensive run time and alternatives should be considered. Future research should also test a larger diameter hose to see if greater flow rate can be achieved with less power. Future research will include more testing on certified equipment for more accurate and formal measurements. Another question that should be addressed in future research is how to ensure consistent quality prints with different users around the world.

\section{Meaning of the design and possible implementation}

The COVID-19 pandemic has taxed the healthcare system and PPE to dangerous levels. If industry is unable to produce the necessary equipment for this, or any other respiratory virus in the future, in a timely fashion, and world PPE supplies are directed towards the highest bidder, we need a better solution that will protect healthcare workers around the world while they perform essential procedures. The Hygieia PAPR should be added to the proposed solutions as an easily reproducible, costeffective and reusable piece of PPE that can be used on its own or to increase the life span and comfort of other essential equipment (ie, N95 masks).

Acknowledgements We would like to acknowledge Daniel Manieri in the Tulane University Office of Environmental Health and Safety for his assistance with testing and data acquisition.

Contributors JN and CG had the idea for the article and completed the PAPR design and testing, data collection, analysis, literature search, and interpretation and writing. JN and CG contributed equally to this project and manuscript and are both guarantors of the overall content. JD contributed to the organisation of the paper, guided testing procedures and protocols, was instrumental in data analysis and interpretation, and writing of the paper.

Funding The authors have not declared a specific grant for this research from any funding agency in the public, commercial or not-for-profit sectors.

Disclaimer The designs and other information ('the Design') made available in this article is at an early stage of development. Accordingly, specific results are not guaranteed, and the Design provided here is provided "AS IS" and without any express or implied warranties, representations or undertakings. As examples, but without limiting the foregoing, Tulane University and their employees and students do not give any warranty or guarantee that the Design is of merchantable or satisfactory quality, is fit for any particular purpose, complies with any sample or description including the requirements for medical device registration, or are viable, uncontaminated, safe or non-toxic, accurate, up to date or complete. Tulane University and the authors have not performed any searches or investigations into the existence of any third-party rights that may affect the Design. Anyone may use the Design entirely at their own risk, and Tulane University and/or the authors are not liable for such use of the Design, including without limitation any direct or indirect losses. Any users of the design should appropriately attribute the author.

Competing interests None declared.

Patient and public involvement Patients and/or the public were not involved in the design, or conduct, or reporting, or dissemination plans of this research.

Patient consent for publication Not required.

Ethics approval This study did not require ethical approval as the only human subjects involved in the study were the authors, minimal to no risk was present, and informed consent was acquired from the authors at the time of original data collection. This work involved testing the equipment on a human subject to validate the qualitative and quantitative testing. The tests were voluntarily performed on the authors and an informed consent was obtained for experimentation. We ensure that the work described has been carried out in accordance with The Code of Ethics of the World Medical Association (Declaration of Helsinki) for experiments involving humans; Uniform Requirements for manuscripts submitted to Biomedical journals.

Provenance and peer review Not commissioned; externally peer reviewed.

Data availability statement Data are available upon reasonable request. Data are available upon request.

Open access This is an open access article distributed in accordance with the Creative Commons Attribution Non Commercial (CC BY-NC 4.0) license, which permits others to distribute, remix, adapt, build upon this work non-commercially, and license their derivative works on different terms, provided the original work is properly cited, appropriate credit is given, any changes made indicated, and the use is non-commercial. See: http://creativecommons.org/licenses/by-nc/4.0/.

\section{ORCID iD}

Catherine Gilbert http://orcid.org/0000-0003-4069-9752

\section{REFERENCES}

1 World Health Organization. WHO Coronavirus Disease (COVID-19) Dashboard [Internet], 2020. Available: https://covid19.who.int/

2 Christie A, Henley SJ, Mattocks L, et al. Decreases in COVID-19 Cases, emergency department visits, hospital admissions, and deaths among older adults following the introduction of COVID-19 vaccine - United States, September 6, 2020-May 1, 2021. MMWR Morb Mortal Wkly Rep 2021;70:858-64.

3 World Health Organization. Rational use of personal protective equipment for coronavirus disease (COVID-19) and consideration during severe shortages [Internet], 2020. Available: https://www. who.int/publications/i/item/rational-use-of-personal-protectiveequipment-for-coronavirus-disease-(covid-19)-and-considerationsduring-severe-shortages

4 Yao W, Wang T, Jiang B, et al. Emergency tracheal intubation in 202 patients with COVID-19 in Wuhan, China: lessons learnt and international expert recommendations. $\mathrm{Br} \mathrm{J}$ Anaesth 2020;125:e28-37.

5 Ranney ML, Griffeth V, Jha AK. Critical supply shortages - the need for ventilators and personal protective equipment during the Covid-19 Pandemic. N Engl J Med 2020;382:e41.

6 McMahon DE, Peters GA, Ivers LC, et al. Global resource shortages during COVID-19: bad news for low-income countries. PLoS Negl Trop Dis 2020;14:e0008412.

7 Calderwood MS, VMD M, Anderson DJ. Policies and practices of SheA research network hospitals during the COVID-19 pandemic. Infect Control Hosp Epidemiol 2020:1-9.

8 American Medical Association. AMA letters: Take immediate steps to address PPE shortage [Press Release], 2020. Available: https:// www.ama-assn.org/press-center/press-releases/ama-letters-takeimmediate-steps-address-ppe-shortage

9 American Hospital Association. Hospitals and Health Systems Face Unprecedented Financial Pressures Due to COVID-19 [Internet], 2020. Available: https://www.aha.org/system/files/media/file/2020/ 06/aha-covid19-financial-impact-report.pdf

10 World Health Organization. Shortage of personal protective equipment endangering health workers worldwide [Internet]. Available: https://www.who.int/news-room/detail/03-03-2020shortage-of-personal-protective-equipment-endangering-healthworkers-worldwide

11 Vordos N, Gkika DA, Maliaris G, et al. How 3D printing and social media tackles the PPE shortage during Covid - 19 pandemic. Saf Sci 2020;130:104870. 
12 Tino R, Moore R, Antoline S, et al. COVID-19 and the role of 3D printing in medicine. 3D Print Med 2020;6:1-8.

13 Erickson MM, Richardson ES, Hernandez NM, et al. Helmet modification to PPE with 3D printing during the COVID-19 pandemic at Duke University medical center: a novel technique. J Arthroplasty 2020;35:S23-7.

14 3M. FiltreteTM allergen, bacteria \& virus true HEPA room air purifier filter, FAPF-HM-K. Available: https://www.filtrete.com/3M/en_US/ filtrete/products/ /Filtrete-Allergen-Bacteria-Virus-True-HEPARoom-Air-Purifier-Filter-FAPF-HM-K/?N=4315+3290256135+ 3294529207\&preselect $=8759816+3293786499 \&$ rt=rudhttps://www. filtrete.com/3M/en US/filtrete/products/ /Filtrete-Allergen-BacteriaVirus-True-HEPA-Room-Air-Purifier-Filter-FAPF-HM-K/?N=4315+ $3290256135+3294529207 \&$ preselect $=8759816+3293786499 \& \mathrm{rt}=$ rud

15 National Institute for Occupational Safety and Health. Statement of standard for chemical, biological, radiological and nuclear (CBRN) Air-Purifying escape respirator, 2003. Available: https://www.cdc. gov/niosh/npptl/standardsdev/cbrn/escape/standard/aperstd-a.html

16 Occupational Safety and Health Administration. 1910.134 appendix - a fit testing procedures (mandatory) [Internet], 2011. Available: https://www.osha.gov/laws-regs/regulations/standardnumber/1910/ 1910.134AppA

17 3M. Guide to using the 3M Qualitative Fit Test Kits [Internet], 2020. Available: https://multimedia.3m.com/mws/media/473960O/guideto-using-the-3m-qualitative-fit-test-kits.pdf

18 Bischoff W, Turner J, Russell GB. Evaluation of a novel powered air purifying respirator (PAPR) vs. a N95 respirator mask for the protection against influenza in a human exposure model. in: IDWeek 2017, HAl. Occup Health 2017;4:S168

19 Wax RS, Christian MD. Practical recommendations for critical care and anesthesiology teams caring for novel coronavirus (2019-nCoV) patients. Can J Anaesth 2020;67:568-76.

20 Licina A, Silvers A, Stuart RL. Use of powered air-purifying respirator (PAPR) by healthcare workers for preventing highly infectious viral diseases - a systematic review of evidence. Syst Rev 2020;9:1-13.

21 Liverman CT, Domnitz SB, Mccoy MA. The use and effectiveness of powered air purifying respirators in health care: workshop summary. 80. Institute of Medicine, 2015.
22 Bharatendu C, Ong JJY, Goh Y, et al. Powered air purifying respirator (PAPR) restores the N95 face mask induced cerebral hemodynamic alterations among healthcare workers during COVID-19 outbreak. $J$ Neurol Sci 2020;417:117078.

23 United State Food and Drug Administration. N95 Respirators, Surgical Masks, and Face Masks [Internet], 2020. Available: https:// www.fda.gov/medical-devices/personal-protective-equipmentinfection-control/n95-respirators-surgical-masks-and-face-masks\#s3

24 Campbell DL, Coffey CC, Lenhart SW. Respiratory protection as a function of respirator fitting characteristics and fit-test accuracy. AIHAJ 2001;62:36-44.

25 Welch JL, Xiang J, Mackin SR, et al. Inactivation of severe acute respiratory coronavirus virus 2 (SARS-CoV-2) and diverse RNA and DNA viruses on three-dimensionally printed surgical mask materials. Infect Control Hosp Epidemiol 2021:42:1-8.

26 Oth O, Dauchot C, Orellana M, et al. How to sterilize 3D printed objects for surgical use? an evaluation of the volumetric deformation of 3D-printed Genioplasty guide in PLA and petG after sterilization by low-temperature hydrogen peroxide gas plasma. Open Dent $J$ 2019;13:410-7.

27 Meyers C, Kass R, Goldenberg D, et al. Ethanol and isopropanol inactivation of human coronavirus on hard surfaces. J Hosp Infect 2021;107:45-9.

28 Cancedda C, Davis SM, Dierberg KL, et al. Strengthening health systems while responding to a health crisis: lessons learned by a nongovernmental organization during the Ebola virus disease epidemic in Sierra Leone. J Infect Dis 2016;214:S153-63.

29 Pun DM. COVID-19 Campaign by NIC Nepal [Internet]. Available: https://nicnepal.org/articles/covid19.html [Accessed 10 Aug 2020].

30 Colton C. Changes. In: Filter testing and certification. 3M JobHealth highlights. , 1998: 16, 1-8.

31 Nazarious MI, Mathanlal T, Zorzano M-P, et al. Pressure optimized powered respirator (proper): a miniaturized wearable cleanroom and biosafety system for aerially transmitted viral infections such as COVID-19. HardwareX 2020;8:23:e00144.

32 Hubbard BR, Pearce JM. Conversion of self-contained breathing apparatus mask to open source powered air-purifying particulate respirator for fire fighter COVID-19 response. HardwareX 2020;8:1-32. 